\title{
Research on College Physical Education Curriculum Reform Based on College Students' Health-related Physical Fitness Improvement
}

\author{
Yongjun Zhao \\ Beijing Institute of Fashion Technology, China. \\ 17526009@qq.com
}

\begin{abstract}
With the continuous development of science and technology, the mechanization levels of all professions and trades have also been continuously improved, especially the rapid popularization and development of the Internet cause the modern people to have less and less physical activity in their work and life, and lead to a trend of declining physical health. "Physical Fitness" aims to train young people to understand the value and significance of lifelong sports activities and develop fitness education; "physical fitness" education can enhance the exchange between college students and society, and can promote college students' recognition of lifelong sports. This paper discusses the introduction of the related concept of physical fitness to the college physical education curriculum, tries to integrate the theory and method of scientific fitness and improve it, and thinks about reforming curriculum system of physical education centered on sports technology teaching, fully mobilize students' interest in learning and stimulate learning motivation, so that students are more interested in physical education.
\end{abstract}

Keywords: Health-related physical fitness, physical education curriculum, reform.

\section{Introduction}

Health-related physical fitness refers to the health-related physical adaptability, which is the precondition for people to work or study. College students are the successors of modernization construction, their physical health problems have always been highly valued by the party and the state. Physical health of college students become worse and worse, and it reflects the deficiency of many aspects of physical education in colleges and universities. Therefore, it is urgent to reform and innovate the university physical education model at this stage, and design the physical fitness education for the healthy development of college students. This research introduces the concept of health-related physical fitness; make an attempt to reform college physical education, and aim to provide valuable empirical references for the curriculum reform of physical education in colleges and universities.

Health-related physical fitness education is a main objective of fitness in the world now, it is an educational program designed to assist physical education teachers help young children understand the value, meaning, and healthy behaviors of lifelong physical activity. It embodies the new trend of lifelong, personalized and healthy development of school physical education curriculum; this is consistent with the basic requirements and development direction of physical education curriculum in colleges and universities in China, which will have a profound impact on the curriculum reform of physical education. "Physical fitness" education is very effective in guiding students to actively participate in sports activities, form a good lifestyle, and promote physical and mental health; it also reflects the new trend of school sports development, namely the lifelong, personalized and healthy sports curriculum. Developing students' physical fitness will have a profound impact on the reform of physical education.

\section{Concept of "Physical Fitness"}

Physical fitness is a general concept that can be divided into health-related physical fitness and skill-related physical fitness two parts, (skill related physical fitness), which refers to the physical fitness for winning competitive advantage, it includes speed, explosiveness, coordination, sensitivity and other qualities; healthy related physical fitness refers to the physical fitness which general people 
improve learning efficiency, work efficiency, prevent disease and promote health, it includes lung function, muscle strength, flexibility and other qualities. Some scholars abroad also think that the components of health-related physical fitness is very important for various sports, but it doesn't mean much about people's daily work or health. Conversely, some scholars have proposed that regular physical activity can improve people' cardio endurance, skeletal muscle capacity and energy metabolism, reduce the risk of common diseases such as heart disease, diabetes mellitus, osteoporosis, cancer and other chronic diseases. Even a good athlete, like a baseball and softball pitcher, golfer, etc., needs to understand that if there is no ideal body fat percentage and cardio endurance, the risk of chronic disease is also high, so different individuals have differences in health-related physical fitness, but aerobic exercise, muscle ability and body composition control can still be used as basic training methods or exercise means.

\section{Relationship between Health-related Physical Fitness and College Physical Education Curriculum}

Health-related physical fitness can be used as the core content of college physical education curriculum, impart physical fitness knowledge for health promotion, meet the knowledge required for physical fitness and health professional work, and train skills and abilities needed for physical fitness and health professional work. Health-related physical fitness is not only the compulsory course for undergraduate physical fitness, but also the training course for community fitness instructors. By studying this course, the college students can master the measurement and evaluation methods of body shape, function and quality in physical fitness, teaching and training process, and provide scientific guidance for individuals, groups and community sports participants in physical exercise, promote people to engage in active, regular, and appropriate sports, and serve the national fitness project in China.

\section{Significance of Health-related Physical Fitness as Reform Content of College Physical Education Curriculum}

Physical education curriculum plays an important role in promoting the improvement of students' physical, psychological, social adaptability and moral quality and so on. Through various sports activities, improve the health level of students, establish a tenacious attitude towards life, improve people's lives and quality of life, and make the existence of life towards a healthy, harmonious, optimistic, perfect realm. This concept is the essence of promoting the development of physical education. Therefore, it is very important to think about how to scientifically and rationally teach sports as a way of promoting healthy thinking, behavior and lifestyle.

The reform of physical education curriculum in China presents the development trend of integration, activity and life, as a reform direction of college physical education curriculum; it can break the current sports teaching system centered on sports sill teaching, manifest the significance of physical and health education, promote the integration of physical and healthy education, emphasizes the combination of physical education, health education and social education, lay stress on the combination of students' physical, psychological, social and sustainable development and promote students' physical and mental development. The physical education curriculum system based on the concept of health-related physical fitness, it does not arrange events according to sports items, but is based on cardio-respiratory strength, strength quality, flexibility and body composition, the teaching and learning are unified, the teaching process of knowledge and skill is harmonious and unified with the training process of exercise and maintenance, and sports awareness, habits and abilities, it is based on the needs of adult life and social life, and points to college students' characteristics, characteristics of college education, the needs of social life, such as cardiovascular disease prevention, cancer risk management, away from tobacco, addictive behavior etc., and it reflect the individualized, life and healthy characteristics. 


\section{Necessity of Launching "Health-related Physical Fitness" Education in Colleges and Universities}

In recent years, the results of physical fitness monitoring of students across the country show that the physical health status of Chinese students is still in decline trend, some physical fitness indicators continue to decline, the detection rate of overweight and obesity continues to rise.

Health-related physical fitness reflects the new trend of the development of physical education curriculum in China's colleges and universities, namely the lifelong, individualized and healthy physical education curriculum. This is consistent with the direction and purpose of China's physical education curriculum reform. Therefore, "health-related physical fitness" education should be regarded as an important content of the physical education curriculum teaching in China's colleges and universities, and it should be implemented carefully and correctly, so that the connotation of its physical education can be fully interpreted in the reform wave of college physical education curriculum, and make it play an important role in the new historical development of sports in China's colleges and universities.

There are many reasons for the decline of students' physical fitness: individual factors, social factors, family factors, and school factors, especially the teaching of physical education in schools. From the analysis of the decline in physical form, physiological function and physical fitness of college students, it is mainly due to the lack of physical exercise, this has the problem of physical exercise time and the activity arrangement, and students also lack their own hard work. In essence, it is a one-sided understanding of the guiding ideology of quality education and health first in college sports theory circles, which leads to the confusion between the purpose and tasks of school sports and mass sports, the virtual healthy concept has replaces the physical fitness concept. This issue has aroused great concern from the party and the government, and it has also posed new challenges for the reform of physical education. This requires us to adhere to the correct direction of physical education reform, seek truth and practical, always focus on "health-related physical fitness" education, and enhancing students' physical fitness as the main goal of physical education reform.

Practice has proved that physical education promotes students' mental health and social adaptation, which has the effect that other courses can't match; therefore, paying attention to "health-related physical fitness" education and enhancing students' physical fitness is still the emphasis of physical education teaching.

\section{Effect of Health-related Physical Fitness Education on the Teaching Reform of Physical Education Curriculum in Colleges and Universities}

Health-related physical fitness education provides theoretical basis and support for meeting the individual needs of students' learning, social development puts forward new requirements for school physical education, and the change in the development of sports, meeting the needs of individual objects has become an inevitable development trend. The emergence of "physical fitness" provides theoretical material for meeting individual needs of students; in order to meet the students' individual needs, it is necessary to classify the different curriculum objectives according to the different situations of the students' physical conditions. According to the division of "physical fitness", it can be divided into two categories: exercise (improvement) and health (promotion). The former should be divided into high-level sports teams (this part of the teaching is the expansion of physical education course in some sense), in fact, because no university will let its sports team students accept regular physical education courses like other ordinary students, if they accept basic part of the physical education curriculum learning according to routine, it is obviously not enough to meet their needs, because they have a higher starting point in "physical fitness" needs. Health type is also divided in allusion to the physical fitness, health status and demand for physical education of college students, the fundamental difference between the health type and the former is that it is not through the physical education curriculum to obtain the "sports fitness". This type of students can also be divided into several levels; the basis of division should be derived from the physical examination and physical 
fitness test at the time of entering the school (or annual). In the division, we should also pay attention to those groups with special conditions (such as obesity, disability or certain diseases) and in psychology (such as depression, anxiety or some mental illness).

Health-related physical fitness education makes the content, form and evaluation criteria of teaching more scientific and flexible; the guiding ideology of the curriculum determines the contents and forms of the curriculum. In view of the revision and supplement of the guiding ideology of physical education curriculum and its historical changes, health-related physical fitness as education form in line with the new ideas, the diversification of its content and the division of educational objects liberate the teachers' teaching ideas, it also causes teachers to adjust the original teaching mode, call them to study the physical education curriculum of ordinary colleges and universities in China, make them more active, and actively consider how to teach to complete teaching tasks and goals, and meet the needs of students. This is especially important for the reform of the physical education curriculum. Health-related physical fitness is based on individual needs, classification and teaching according to the actual situation and needs of students. For students, the first thing is to break their fear to physical education, make them realize physical education is an important channel for obtaining health, understanding and learning to use healthy resources, mastering certain modern sports knowledge and certain sports technical skills, rather than obtaining diploma, so that students become active, in addition, the transformation of teachers' teaching thoughts enables the two sides of the teaching and learning to integrate organically and develop in a reasonable direction. Therefore, the teaching form will be more active in content and methods, and leave the rigid form of traditional teaching routines.

\section{Health-related Physical Fitness Makes Physical Education Curriculum Reform more Specific and Easier to Achieve}

The educational objects are classified according to the "physical fitness"; its purpose is to aim at students with different physical conditions and sports foundation; achieve different teaching goals by different teaching content and form, make the teaching goal more focus on individual students, and make the physical education more personalized.

In the past teaching, due to the influence of the old teaching mode, the teachers are forced the use limited class in students, make a considerable number of students took little time to master a number of competitive sports that are difficult to grasp in a short period of time, make the physical education class become a test lesson in some form, the class has become a test class or even a 'standards' course, and induce students to mistakenly believe that the physical education class is to pass examination; make teaching and learning both sides seriously ignore the important goal "health" of physical education; therefore, it is difficult for students to achieve physical education through physical education curriculum. Students sigh "like sports, but does not like physical education classes". According to the classification defined by health-related physical fitness, the sports curriculum carrier has been expanded to provide students with new health care services, provide new guiding ideology and content; and make learning objectives closely related to students (individuals), students are willing to accept and relatively easy to implement, thus making the goal of physical education easier to achieve.

The guiding ideology of the course determines the content and form of the course. Considering the revision and supplement of the guiding ideology of physical education curriculum and its historical changes, health-related physical fitness is in line with the new ideas, the diversification of its contents classify educational objects, liberate the guiding ideology of teachers' teaching, and causes teachers to review the original teaching mode, make them more actively consider how can complete teaching tasks and goals and meet students' needs. This is especially important for the reform of the physical education curriculum, because the teacher is main body of teaching reform. 


\section{Conclusion}

Health-related physical fitness is a comprehensive indicator of health evaluation from the perspective of physical education, which is the ability which the body perform its functions effectively and efficiently, and it is also an ability of the body which adapt to the environment. The concept of health-related physical fitness is more and more accepted by college students, the future physical fitness will have broad prospects, for this reason, it is necessary to continue to improve the theoretical and practical teaching system, strengthen the development and application of online courses and multimedia-assisted teaching software, and vigorously carry out extracurricular teaching practice activities. The curriculum setting of health-related physical fitness should pay attention to the college students' various needs, interests, creation and freedom, and attach importance to the development of college students' personalized development.

\section{References}

[1]. Lan Rong, Zhang Liguang, etc. The Explanation of Fitness in the Sports Exercise and Training [J]. Journal of Guangzhou Physical Education Institute, 2004 (3): 125-126.

[2]. Xie Jingyue. Reform and Innovation of Public Physical Education Curriculum in Colleges and Universities [J]. Journal of Physical Education, 2002 (6): 98-99.

[3]. Chen Xiaohu. Simply Discuss on Related Physical Fitness and Physical Course Reform [J]. Zhejiang Sport Science, 2006 (2): 50-51.

[4]. Liu Ling. Discussion on the Reform of Physical Education in Colleges and Universities in China [J]. Success (educational edition), 2011 (23):12-13.

[5]. Wang Yali. The U.S. Model of Health-related Physical Fitness Programs in Our Colleges and Universities, Experimental Study [J]. Sports \& Science, 2010, 31(1): 104 -108. 